body shook convulsively, even the muscles of his neck quirering, and his face was for the first time slightly cyanosed. Previously he had been taking nourishment freely, bat daring the last few hours all food was rejected. On the administration of chloroform the hiccough ceased, but the inbalation was discontinued after a quarter of an hour on account of the shallowness of his respirations, and in less than an hour the hiccough was as bad as ever. At my next risit I was accompanied by a medical friend. No sooner had we entered the patient's room than the hiccough ceased, nor did it return during the ten minutes or so that we remained there; bat it recarred with unabated severity on our departure. Probably the arrival of two medical men agitated the patient and acted on him as a temporary counter-irritant. In accordance with my friend's suggestion I endeavoured to administer tincture of belladonna in combination with aromatic spirit of ammonia; but the mere sight of the medicine produced painful retching. I therefore again injected half a grain of morphia under the skin of the arm and used chloroform inhalation. The morphia caused drowsiness, bat no sleep, and although the hiccough ceased while the chloroform was being given, it returned in all its former argency as soon as the unconsciousness passed off. The patient now seemed to be in a critical state. No nourishment of any sort had been taken for many hours, and the cyanosis was intense, while the hiccongh was continuous and violent. I then sought the advice of three triends of hospital experience to whom I described the case. They recommended the successive trial, in the following order, of (1) ice to the phrenics; (2) galvanism to the same region (3) dry cupping to the loins, on the chance that there might be latent kidney mischief ; (4) drachm doses of subnitrate of bismuth; and (5) the prolonged inhalation of chloroform short of producing narcosis. It was impossible for the patient to swallow the bismuth, and the chloroform had been pushed as far as I was disposed to venture. The other recommendations were carried out, but did not produce the slightest apparent benefit. As a final resource I then injected below the skin of the arm six minims of a solution containing ore-sixtieth of a grain of atropia and half a grain of morphia. The dose was large certainly, but the same quantity of morphia had been already injected without producing any further $\epsilon$ ffect than a little drowsiness. In five minates the patient was fast asleep, and the hiccough had entirely ceased. In rather less than two hours I returned, in response to an urgent summons, and found his face cyanosed, his lips particularly blue, and his breathing stertorous, and so slow and laboured that he seemed to be on the point of suffucation. There was, however, no clammy perspiration, and the pulse was comparatively strong, slow, and regular; the pupils were slightly dilated and quite insensible to light. He could not be wakened by slapping the face with wet towels, shouting into the ears, or applying galvanism to the temples, but tickling the soles of the feet made him start so violently that he regained sufficient consciousness to answer a few question and swallow a little coffee. He was allowed to fall asleep once more, but in about an hour his breathing became so much obstructed that he was again awakened, this time with far less difficulty than before. He talked for a few minutes quite rationally, drank some beef-tea, and fell asleep again. Next morning he complained of nothing except some stiffiness of the neck and diffiulty in swallowing. There was no return of the hiccough, which had lasted for seventy-two hours without cessation, except during the short periods while he was under chloroform and while he was visited by my medical friend and myself together. His subseqnent improvement was rapid, and in a few days he regained his normal condition.

Camden-town.

\section{ANESTHESIA BY THE CHLOROFORM AND ETHER MIXTURE.}

BY EDGAR B. TRUMAN, M.D. ST. AND., F.I.C., F.C.S., PTBIIC ANALYST FOR THE BOROUGH OF NOTTINGHAM, AND SURGEON TO THE SAMARITAY HOSPITAL FOR WOMEN, NOTTINGHAM.

THe large number of deaths from chloroform administration that has been noticed lately has caused anæsthetists to look out for a safer aræsthetic. A mixture of 1 volume of chloroform and 2 of ether has been used under the impress.on that the vapour inhaled would consist of 2 volumes of ether and 1 of chloroform, and in that way the depressing action of the chloroform upon the heart would be neutralised by the stimulating action of the ether. To the chemical mind this would seem most unlikely. Ether boils at $35^{\circ} \mathrm{C}$. $\left(95^{\circ} \mathrm{F}\right.$.) and chloroform at $62.7^{\circ} \mathrm{C}$. $\left(145^{\circ} \mathrm{F}\right.$.), and it seems highly probable that the ether would vaporise out of all proportion to the chloroform. In the administering of an anæsthetic there are two factors which determine the assumption of the vaporous condition. The first of these is the property of diffusion, by which a body capable of volatilisation becomes diffused through an adjacent gas or vapour. The said body may be solid or liquid. During a hard frost it is matter of notoriety that snow will gradually disappear by evaporation. Water, in the same way, volatilises at ordinary temperatures. It is known that gases or vapours diffuse with a velocity inversely as the square root of their densities. The density of ether vapour being 37 and that of chloroform being $59 \cdot 75$, and their square roots 6.082 and 7.729 respectively, it follows that ether vapour will diffuse to chloroform vapour as $7 \cdot 729$ to 6.082 , or as 100 to 788 . So far, then, as regards diffusion, the vapour of the ether will preponderate. The second factor is the boiling point. To determine the relative proportion of the mixed vapours as occurring during the administration of the mixture I have made one or two experiments, which I will now detail.

Ether having a specific gravity of 0.72 and chloroform one of 1.497, two volumes of ether and one of chloroform will be very nearly of the same weight. I took equal weights66 c.c. of chloroform and 137.2 c.c. of ether-putting the chloroform into a long, slender, stoppered vessel graduated in c.c. with a thermometer, whose volume was ascertained, as it had to be immersed in the mixed liquids. I then carefully poured in the ether, which lay above the chloroform without mixing with it. The volume then (subtracting the space occupied by the thermometer) at $18^{\circ} \mathrm{C}$. was 203.2 c.c. On mixing by turning upside down a few times, the thermometer rose to $28^{\circ} \mathrm{C}$., and the volume of the liquid increased. Oa cooling down to $18^{\circ}$ the volume contracted down to the original volume of 203.2 c.c. I took a flask having a capacity of 1200 c.c., intending by the space thas obtained to give an opportunity for the same diffusion to take place as occurs during the administration of anæsthetics. Into this flask, which had a side tube in the neck for distillation, I introduced the mixture, closed the flask with a stopper carrying a thermometer reaching down into the centre of the flask, and c onnected the side tube with a glass condensing apparatus. I then placed a small water bath under the flask, and applied gentle heat. The flask was raised a little distance from the water bath, and the temperature was kept between the limits of $36.6^{\circ}$ and $40^{\circ} \mathrm{C}$. $\left(98^{\circ}\right.$ and $104^{\circ} \mathrm{F}$.). The heat was so gentle that the distillate came over slowly, the first 50 c.c. coming over in seventy-fire minutes, the next 25 c.c. in sixty minutes, and the last 10 c.c. in twenty minutes. When these 85 c.c had come over distillation ceased, the thermometer reading being $40^{\circ} \mathrm{C}$. The specific gravity of the distillate was 0.7344 . This denotes a mixture by weight of 1.87 chloroform and 98.13 ether, by volume 1.87 chloroform and 196.26 ether; in other words, 100 volumes of ether to 0.953 chloroform-i.e., less than 1 per cent That chloroform was present in the distillate, and that its higher density was not due, or not due solely, to the alcohol which chloroform is allowed to contain, was shown by two tests : (1) formation of benzo-isonitrite by warming with alcoholic soda and phenylamine; and (2) reduction of Fehling's solution. The residue in the flask was next examined. It amounted to 103 c.c. The specific gravity was $1 \cdot 187$, equivalent to a mixture by weight of 60 chloroform and 40 ether, by volume 60 chloroform and 80 ether, or 100 volumes of ether to 75 of chloroform. Thus, administering this mixture, the patient would be inhaling 100 volumes of ether to 0.953 of chloroform at the first; whilst if the whole of the contents were used up the patient at the last would be inhaling 100 volumes of ether to 75 of chloroform.

1 Since writing the above I hare examined the residues left in Clover's apparatus in three administrations of the mixed anæsthetics. The specific gravities were $1 \cdot 144,1 \cdot 095$, and $1 \cdot 028$, giving the respective quantities of ether to chloroform by weight as $45^{\circ} 3$ to $54^{\circ} 7$, as $51 \cdot 7$ to $49 \cdot 3$, and as 59.5 to 40.5 ; or by volume as 90.6 to 54.7 , as 103.4 to 49.34 and as 119 to 40 ; that is, to 100 volumes of ether, $50,47 \cdot 6$, and 3 , volumes of chloroform respectively, in the state of vapour. The residue first examined, as stated above, contained 100 volumes of ether to 75 of chloroform. These cases show conclusively that in administering the mixed anæsthetics we are using a vapour of varying and uncertain
composition. 
Ccnsideration of these figures must show as the inadvisability of using the mixture of ether and chloroform. To be giving an inhalation which may vary between 100 to 0.9 and 100 to 75 is clearly a most dangerous proceeding. It appears to me that for ordinary cases ether is by far the safer anæsthetic of the two; that when this is contra-indicated, pure, unmixed chloroform should be used, every precaution being taken as in the case of all anæsthetios, to give it carefally ; but that to use the two mixed is unscientific and nnsafe. In these remarks I have had in view administration by Clover's inhaler. In giving the mixture by dropping it on to an open flanrel mask the vapours would doubtless be more evenly distributed.

Derby-road, Nottingham.

\section{Clinital atotes:}

MEDICAL, SURGICAL, OBSTETRICAL, AND THERAPEUTICAL.

\section{A CASE OF TRAUMATIC INTRA-PERITONEAL H ÆMORRHAGE.}

By E. H. Wagstaff, M.R.C.S. Eng.

IN connexion with Mr. Battle's case of Intra-peritoneal Hæmorrbage in THE LANCET of Jan. 26th a sketch of the following case, which occurred recently in my practice, might be of interest.

A man met with an accident under the following circumstances. On Dec. 19th, 1893, whilst driving in an ordinary spring cart his horse stumbled and fell, whereupon he jumped from the cart and fell on the road on his left side. Assistance was immediately at hand, and he was conreyed-in a sitting position in another cart-to his home, a distance of about two miles and a half. I saw him immediately on his arrival and found that he had sustained a fracture at the junction of the middle and upper thirds of the left femur, which was promptly put into position. A careful examination was made, but no further injury could be made out. It was remarked at the time that there was an entire absence of shock. The patient was warm, and the pulse, temperature, and respiration were normal an hour after being put to bed ; indeed, he was extrasrdinarily cheerful considering the circumstances. The friends report that, though a generally healthy man, he suffered from flatulent dyspepsia and want of appetite, evidently the result of alcoholism, his tendencies in that direction being well known. All went well until Dec. 21st, when slight romiting set in with flatulence, the forme relieving the latter. No abdominal pain was complained of. There was no dulness or undue distension of the abdomen. As the bowels had not been open since the accident an aperient was given, but without effect. The vomiting recurred at intervals until the morning of the $22 \mathrm{nd}$, when it ceased, but the bowels continued obstinate. The romiting recommenced in the early morning of the 23rd, and continued at intervals throughout the day. During the whole of this time the pulse varied between 72 and 85 , and the temperature between $97.8^{\circ}$ (after vomiting) and $994^{\circ} \mathrm{F}$.; the tongue was moist and fairly clean, and the respiration was normal. At 8.45 P M. on the 23rd the patient complained of faintness, and, on my visiting him at 9.30 , to my surprise I found him cold, pulseless, and collapsed, in fact in extremis, from which condition he never rallied, but died at 10.45. The necropsy (twelve hours after death) revealed nothing of moment on first opening the abdomen. There was no peritonitis The stomach bowels, spleen, liver, and kidneys were healthy, the latter wonderfully so, considering the alcoholic habit. A small length of bowel above the cæcum was collapsed, but there was no undue fæcal accumulation. On tracing the bowel upwards to the duodenum with a view to its removal a large retro-peritoneal hæmorrhage was discovered in connexion with the pancreas. It was impossible to define its precise origin, as the whole organ was so bruised and lacerated as to break up on handling. Here was evidently the cause of death, an accident in itself perhaps worthy of record; bot I venture to suggest that the chief interest lies in the absence of any of the ordinary symptoms attending so extensive a lesion of so important an organ. The bruising and laceration of course occurred at the time of the accident, whilst the hæmorrhage probably occurred a few hours before death as the result of inflammatory changes or the effort of romiting.

Leighton Buzzard.

INVERSION OF UTERUS; DEATH. By Theodore Maxwell, M.D. CaMrb., F.R.C.S. Edis.

THOUGH I can hardly think that cases of complete incersion of the uterus are as rare as one in 150,000 , as has been stated, they are quite rare enongh and fatal enough to justify my recording the following one. I find a similar case mentioned by Dr. J. L. Kerr ${ }^{1}$ of Crawshawbootb, Manchester, where, how: ever, the woman died ten minutes after replacement from shock and hæmorrhage, and where there was a suspicion that the midwife had pulled at the cord, which I feel sure she did not do in my case. I was called at 6 A M. on Jan. 26 ch last by a midwife to a young woman in her first confinement, and found the child, which was somewhat premature, born, the woman very pale and low, and the afterbirth, which was to a large extent invested by the membranes, hanging out of the vulva. On this mass gentle traction had no effect. Pinching it near the vulva caused pain, and there was no tumour to be felt above the pubes. I then passed my finger cautiously into the vagina, and found, as I suspected, that there was no os, but that the mass was continuous with the fornix and consisted of the inverted uterns, with the placenta partly attached. I found no difficulty in peeling off the latter, and very little in replacing the uterus by the pressure of three fingers. It was, however, so soft and flabby that it could not be felt through the abdo. minal walls. I syringed out the vagina with a hot solution of creolin and administered a little ergotin and scme egg and spirit, but death occurred in about an hour. There was no hæmorrhage at any time. The midwife said that the labour was a breech case and extremely easy, there being very little pain. The child was born about 5 o'clock, and as the afterbirth did not come and there was no pain or bæmorrhage she proceeded to wash the infant. While doing so the placental mass appeared. She had once seen a case of inversion, and had a suspicion of what had occurred and therefore sent for me at once.

Woolwich-common, Kent.

\section{CASE OF ACUTE ALCOHOL POISONING.}

By Norman Kerr, M.D. Glasg., F.L.S.

A WOMAN aged forty-one years, wife of a labourer, a periodic inebriate, on Dec. 19th, 1894, in London, drank one and a half pints of whisky 22 over proof (47 stronger than whisky as usually retailed). As this is nearly double the ordinary retail spirituous strength, she must have swallowed more than two and three-quarter pints of the latter. The spirit was taken right off. In a few minutes she was found lying on her back insensible, and never recovered consciousness till she died five and a quarter hours later. The post-mortem appearances thirty hours after death were venous engorgement of the head, with subarachnoid effusion, in addition to old-standing congestion, with white, milk-like film on the surface of the pia mater. The walls of the heart were fatty, pale, and thickened. The carities contained about half an ounce of fluid, tarry-like blood in the right ventricle. There was slight pleural effusion in the lungs, and patches of extravasation of blood in both. The walls of the stomach, which were thinned in parts, with patches of mucous membrane semi-detached, presented brownish-black ridges, with a red, fiery, tree like aspect, on a transiucent, pale, interspersed with red ground, corrugated inflammatory appearances extending into the duodenum. The stomach contained eight ounces of grumons fluid with a faint odour of alcohol. The spleen was engorged. The capsule of the kidneys was semi-adherent. While the patient was alire the face was pale, the eyes suffused and dull, the skin cold and clammy, with cold perspiration, the pulse thin ard compressible, almost imperceptible, and the breathing stertorous. Throughout the pupils were dilated. The temperature fell $7^{\circ} \mathrm{F}$. below normal.

Regent's-park, London, N.W. 